\title{
PARASAGITTAL CORTICAL ATROPHY: A CAUSE OF "PRIMARY LATERAL SCLEROSIS"
}

\author{
HeLIO LEMMI * \\ RICHARD DALY * \\ ROBERT ANG**
}

Currently the problem of the existence of primary lateral sclerosis as a distinct clinical entity is not a matter of much controversy. It seems generally accepted that what was once regarded as a disease process characterized by selective degeneration of the pyramidal tracts is usually, if not always, but one manifestation of a number of well defined diseases, such as amyotrophic lateral sclerosis, multiple sclerosis, subacute combined degeneration of the cord, etc. However, it is not very long ago that such keen observers as Wechsler and Brody ', and Stark and Moersch 2, having followed a fairly large number of cases exhibiting no abnormalities other than bilateral pyramidal tract signs over periods of several years, were convinced that primary lateral sclerosis existed as a separate disease state. No convincing pathological material has yet been presented to support their conviction. Greenfield ${ }^{3}$, and Brain ${ }^{4}$ both ignore the problem. Walshe ${ }^{5}$ expressed the opinion that "...most cases so labeled ultimately prove to be amyotrophic lateral sclerosis or some other known affection of the nervous system, and the title corresponds to no special recognized pathologic process and should be abandoned." Merritt ${ }^{6}$ has a very similar view. The unusual features of the following case illustrate the hazard involved in the liberal use of this diagnosis.

\section{CASE REPORT}

W.C., a 54 year old white male, was admitted to the Neurology Service, John Gaston Hospital, Memphis, Tennessee, on January 4, 1961. His only complaint at that time was marked difficulty in walking, due to what he described as tightness and shaking of both lower extremities. At the age of 7 years he suffered a severe illness of about 8 weeks duration characterized by a high fever and clouding of consciouness. Immediately following this it was noted that he had difficulty in

* Assistant Professors of Neurology. University of Tennessee Medical School, U.S.A.; ** Resident in Neurology. 
everting the left foot, and there was moderate weakness of the left lower extremity. Further details regarding the acute illness were not available. A slight difficulty with gait persisted, but there were no signs of progression until, at about the age of 15, he began to experience feelings of tightness and shaking in the left lower extremity on exertion. About 20 years ago the same type of disability in the right lower extremity developed gradually. Since that time, sudden marked increases in severity have punctuated long intervals during which the disorder remained stationary, but there have been no periods of remission. There was no history suggestive of bladder, bowel, or sexual dysfunction, and no other complaints referable to the nervous system. Examination - The general physical examination was within normal limits. There was no mental deficit. The gait was slightly wide based, slow and markedly spastic. Associated movements of the upper extremities were normal. Very brisk deep tendon reflexes in the lower extremities were associated with severe bilateral clasp-knife spasticity, sustained patellar and ankle clonus, extensor toe responses, and clonic movements of the legs on voluntary extension. The abdominal reflexes were active. There was a slight varus deformity of the left foot. The remainder of the neurological examination revealed no additional abnormalities. Laboratory data - Routine analysis of the blood, urine and cerebrospinal fluid were all within normal limits. Skull, spine and chest X-rays were normal. Myelography of the entire spinal subarachnoid space revealed no evidence of pathology. The patient was discharged on January 22, 1961 as "undiagnosed disease of the nervous system", although the possibility of this being a true case of primary lateral sclerosis was considered.

2nd Admission - The patient continued to complain of increasing disability, and although there were no new findings, he was admitted for reevaluation on March 4, 1962. Electromyography of the left extensor digitorum brevis, both anterior tibials, and the left quadriceps, and nerve conduction studies of the left peroneal nerve revealed no evidence of lower motor neurone involvement. Two electroencephalograms, the second employing several exploratory electrodes in the parasagittal areas, revealed only a focus of theta activity in the right occipital region, but no other abnormalities. Pneumoencephalography demonstrated rather marked dilatation of the posterior region of the right lateral ventricle, particularly in the area of the trigone, multiple widened sulci over the right hemisphere, and a prominent crescent of air over the right insula. However, more remarkably there was the accumulation of bilateral and fairly symmetrical pockets of subarachnoid air, about 2 centimeters in diameter, lying just lateral to either side of the falx, and slightly anterior to the vertex. Bilateral carotid angiography, including very satisfactory venous phases, showed no abnormality. The patient was discharged on April 3, 1962 with a presumptive diagnosis of thrombosis of the superior sagittal sinus, recanalized.

\section{DISCUSSION}

The bilateral parasagittal accumulations of subarachnoid air, indicated by the arrows in Fig. 1, were thought to be a unique finding. Davidoff and Epstein ${ }^{7}$ make no reference to such a phenomenon, and a search of the literature failed to reveal a description of this abnormality. Consideration of the normal projection of the cerebral fissures and sulci on to the surface of the skull indicates that the obvious localized atrophic areas lie slightly anterior to the precentral gyri. Because of this localization, it was reasoned that there certainly must be a causal relationship between the evident pathology and the patient's clinical signs and symptoms. It was further deduced that in the light of what is known of neuropathological processes, a vascular lesion would be by far the most likely cause of such 
a localized atrophic process, and that previous occlusion of the superior sagittal sinus would best account for the clinical and pneumoencephalographic findings.
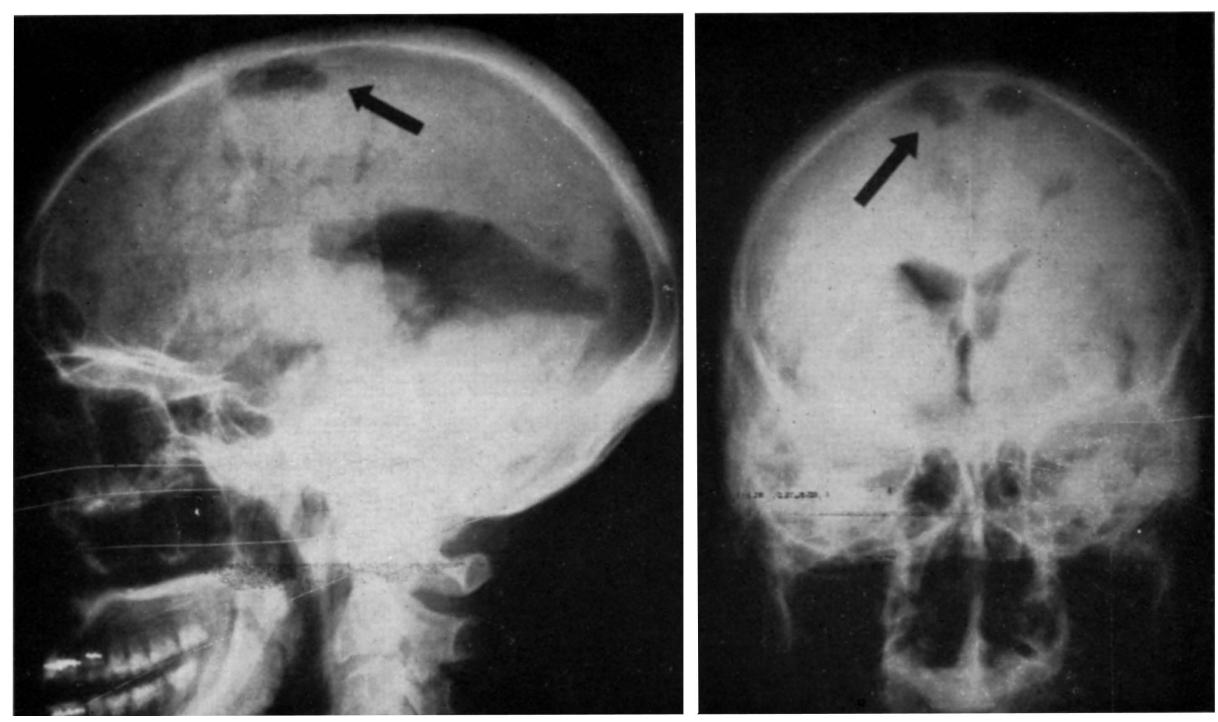

Fig. 1 - W.C. Pneumoencephalogram demonstrating large bilateral accumulations of air in the parasagittal region. Note also the marked enlargement of the right trigone and several widened sulci.

Consideration of the work of Bailey and Hass 8 lends support to this conclusion. In one of their cases studied pathologically it was demonstrated that a thrombus in the superior longitudinal sinus can extend to adjacent veins, "even at some distance from the superior longitudinal sinus". These investigators also concluded that if a patient can survive for at least a few weeks, there will be recanalization of the occluded sinus. The experimental studies of Owens et al. ${ }^{9}$, Beck and Russel ${ }^{10}$, and Denny-Brown ${ }^{11}$, using different techniques to occlude the flow of blood in the superior longitudinal sinus in a variety of animals, again showed rapid organization and recanalization of the thrombi in most instances.

Obstruction of the superior longitudinal sinus in its posterior two-thirds frequently results in infarction of the areas drained by the sinus, with subsequent tissue necrosis, liquefaction and reabsorption. Secondary hemorrhage may occur into the wall of the sinus (Carrie and Jaffe ${ }^{12}$ ) and into the necrotic cerebral tissue, as occurred in the cases of Bailey and Hass. They also described the lesions as extending as deep as the white matter, leaving a communication with the subarachnoid space. A portion or all of a gyrus may be involved in the atrophic process; necropsy examination reveals marked shrinkage at the affected sites. 
In our opinion, the pneumoencephalographic demonstration of markedly atrophic areas in the brain of the patient under consideration can not be disputed. The location, distribution, and gross nature of the lesions coincides strikingly with the pathology occurring subsequent to obstruction of the superior longitudinal sinus. We would also like to stress that the clinical picture has been one characterized by chronic progression over a period of about thirty years. Assuming that the existence of "primary lateral sclerosis" is a fiction, it appears extremely unlikely that any of the other numerous causes of what Courville 13 has termed the "parasagittal syndrome" could account for the prolonged course in this case. Furthermore, the exclusive involvement of the lower extremities is well accounted for by the bilateral, symmetrical, parasagittal lesions. The additional areas of atrophy in the right hemisphere seen in the pneumoencephalogram coincide well with typical autopsy material (Fig. 2), in which asymmetrical involvement of the hemispheres is very common. And considering what is known regarding recanalization of the thrombosed superior longitudinal sinus, angiographic demonstration of a patent sinus in this case does not conflict with our diagnosis.

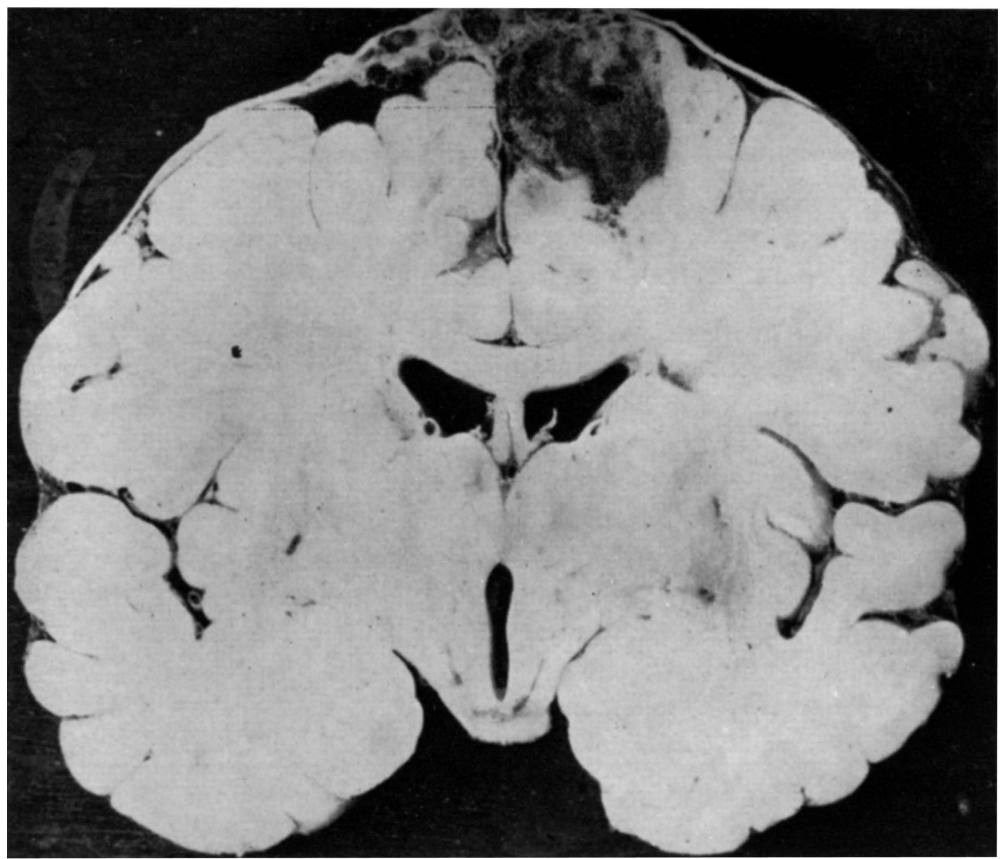

Fig. 2 - Coronal section of a brain showing the asymmetrical parasagittal lesions secondary to thrombosis of the superior longitudinal sinus.

It should be emphasized that except for the febrile illness at the age of 7 , and the present clinical condition, this patient has no history of serious 
illness. The etiology of the earlier disease remains a matter of speculation, but it seems likely that a febrile condition of 8 weeks duration may have been associated with a degree of inanition, a circumstance well known to be accompanied by the development of venous sinus thrombosis. Byers, commenting on the paper by Ray and Dunbar ${ }^{14}$, stated that in a study of 50 cases of thrombosis of the superior Iongitudinal sinus at the Children's Hospital in Boston, there was "extreme diversity of symptomatology as compared to pathology". There is a corresponding wide variety of late sequelae in those surviving the illness, and the absence of deficits other than severe motor impairment in our patient suggests only that the original illness was not a severe, diffuse encephalitis, as typified by numerous viral diseases. That the disturbance of consciousness during the acute illness may have been secondary to occlusion of the superior longitudinal sinus seems probable 15, 16, 17. Infections about the head, or trauma to the head as causes of venous sinus thrombosis are mentioned by several authors 18, 19, 20, 21. By history, neither of these etiologies were operative in this case. Other more remote causes are included in an extensive list given by Ford ${ }^{22}$.

This patient is considered as an unusual clinical case coupled with a remarkable pneumoencephalogram. It would be naive to assume that the diagnosis has been definitely established. However, we hope to have pointed to the need for careful and extensive studies in cases presumed to be "primary lateral sclerosis", and to have demonstrated the usefulness of pneumoencephalography in studying one type of cerebrovascular disease.

\section{SUMMARY}

A case of severe spastic paraparesis of the lower extremities is presented as an example of the late sequelae of thrombosis of the superior longitudinal sinus. Evidence in support of this presumptive diagnosis is given by analysis of the clinical history and the remarkable pneumoencephalographic findings. This case affords the opportunity to stress the need for caution and restraint in the use of the diagnosis "primary lateral sclerosis".

\section{RESUMO}

Os autores apresentam um caso de paraparesia espástica instalada lentamente como seqüela tardia de trombose do seio longitudinal superior. $O$ diagnóstico etiológico foi baseado na evidência oferecida pela história e em relação a vários trabalhos clínicos e experimentais publicados anteriormente e discutidos pelos autores. Os achados pneumencefalográficos corroboram perfeitamente o diagnóstico. Êste caso oferece a oportunidade para chamar a atenção sôbre a necessidade de cautela quando se faz o diagnóstico de "esclerose lateral primária" da medula em paciente que apresente paraplegia crural epástica. 


\section{REFERENCES}

1. WECHSLER, I. W.; BRODY, S. - The problem of primary lateral sclerosis. J.A.M.A., 130:1195, 1946. 2. STARK, F. M.; MOERSCH, F. P. - Primary lateral sclerosis; a distinct clinical entity. J. Nerv. \& Ment. Dis., 102:332, 1945. 3. GREENFIELD, J. G. - Neuropathology, ed. 1. Edward Arnold Ltd., London, 1958. 4. BRAIN, R. - Diseases of the Nervous System, ed. 5. Oxford University Press, London, 1955. 5. WALSHE, F. M. R. - Diseases of the Nervous System, ed. 8. Williams and Wilkins Co., Baltimore, p. 240. 6. MERRITT, H. H. - A Textbook of Neurology, ed. 2. Lea \& Febiger, Philadelphia, 1959, p. 484. 7. DAVIDOFF, L. M.; EPSTEIN, B. S. - The Abnormal Pneumoencephalogram, ed. 1. Lea \& Febiger, Philadelphia, 1950, pp. 356-363. 8. BAILEY, O. T.; HASS, G. M. - Dural sinus thrombosis of the superior longitudinal sinus and its relation to certain acquired cerebral lesions in childhood. Brain 60:293, 1937. 9. OWENS, G.; STAHLMAN, G.; CAPPS, J.; MEIROWSKY, A. M. - Experimental occlusion of dural sinuses. J. Neurosurg., 14:640, 1957. 10. BECK, D. J. K.; RUSSELL, D. S. - Experiments on thrombosis of longitudinal sinus. J. Neurosurg., 3:337, 1946. 11. DENNY-BROWN, D.; HORENSTEIN, S.; FANG, H. C. H. - Cerebral infarction produced by venous distention. J. Neuropath., 15:146, 1956. 12. CARRIE, A. W.; JAFFE, F. A. Thrombosis of superior sagittal sinus (caused by trauma without penetrating injury). J. Neurosurg., 11:173, 1954. 13. COURVILlE, C. B. - The parasagittal syndrome. Bull. Los Angeles Neurol. Soc., 8:31, 1943. 14. RAY, B. S.; DUNBAR, H. S. Thrombosis of the superior sagittal sinus as a cause of pseudotumor cerebri: methods of diagnosis and treatment. Trans. Amer. Neurol. Ass., 75:12, 1950. 15. SMITH, J. C. - Primary cerebral thrombophlebitis. J.A.M.A., 148:613, 1952. 16. PRICK, J. J. - The so-called spontaneous (sive primary) thrombosis of the sinus longitudinalis superior and its tributary pial veins. Folia Psychiat. et Neurol., 58:259, 1955. 17. MARTIN, J. P. - Lesions veineuses cerebrales sans infection. Rev. Neurol., 80:433, 1948. 18. STUART, E. A.; O'BRIEN, F. H.; McNALLY, W. J. Cerebral venous thrombosis: its occurrence; its localization; its source and sequelae. Ann. Otol. (St. Louis) 60:406, 1951. 19. HOLMES, G.; SARGENT, P. - Injuries of the superior longitudinal sinus. Brit. Med. J., 2:493, 1915. 20. WHARTON, H. R. - Wounds of the venous sinuses of the brain. An analysis of seventy cases. Ann. Surg., 34:81, 1901. 21. CAIRNS, H.; CALVERT, C. A.; DANIEL, P.; NORTHCROFT, G. B. - Complications of head wounds, with special reference to infection. Brit. J. Surg., War Surg. Suppl., 1:198, 1947. 22. FORD, F. R. - Diseases of the Nervous System in Infancy, Childhood and Adolescence, ed. 4. Charles C. Thomas, Springfield (Illinois), 1960, p. 888.

University of Tennessee Medical School, Division of Neurology - Memphis 3, Tenn. - U.S.A. 